\title{
Disambiguating with Bourdieu: unravelling policy from practice in the teaching of children with English as an additional language
}

Article

Accepted Version

Flynn, N. (2015) Disambiguating with Bourdieu: unravelling policy from practice in the teaching of children with English as an additional language. Literacy, 49 (1). pp. 20-27. ISSN 17414369 doi: https://doi.org/10.1111/lit.12049 Available at https://centaur.reading.ac.uk/44082/

It is advisable to refer to the publisher's version if you intend to cite from the work. See Guidance on citing.

Published version at: http://onlinelibrary.wiley.com/doi/10.1111/lit.12049/full

To link to this article DOI: http://dx.doi.org/10.1111/lit.12049

Publisher: Wiley-Blackwell

All outputs in CentAUR are protected by Intellectual Property Rights law, including copyright law. Copyright and IPR is retained by the creators or other copyright holders. Terms and conditions for use of this material are defined in the End User Agreement. 


\section{CentAUR}

Central Archive at the University of Reading

Reading's research outputs online 
Flynn N. (2015) Disambiguating with Bourdieu: unravelling policy from practice in the teaching of children with English as an additional language, Literacy, 49, 20-27, doi: $\underline{10.1111 / \text { lit.12049 }}$

\section{Disambiguating with Bourdieu: Unravelling policy from practice in the teaching of children with English as an additional language (Literacy Special Issue: Methodology Matters)}

This article explores the use of Bourdieusian analysis for examining how policy and practice interact in the teaching of English and therefore in the development of children's language and literacy; in particular how Bourdieusian analysis uncovers the ways in which teachers' practice has been influenced unconsciously by centralised shaping of the curriculum for English in England while the pupil demographic in schools has become more linguistically diverse. Data were collected from interviews with both newly qualified and very experienced primary school (pupil ages $5-11$ ) teachers, whose pedagogical norms for the teaching of English were challenged by the

arrival of non-English speakers in their classrooms. The discussion highlights how the use of Bourdieusian constructs of field, habitus and capital can disambiguate teachers' practical classroom decisions from the influences of policy expectations.

Keywords: Bourdieu, grounded theory, curriculum for English, English as an additional language (EAL)

\section{Introduction}

The use of Bourdieu's analytical toolkit, his 'logic of practice' (Bourdieu, 1990), in educational research has gathered momentum in the past decade, not least because his constructs of field, habitus, and capital are valuable interpretive instruments when used to uncover the unconscious 
and the invisible in education (Grenfell \& James, 1998). Bourdieusian analysis is also viewed as powerful in exploring the inter-relationship of practice and the written text of policy, and how this plays out in the classroom (Gerrard \& Farrell, 2012). Furthermore, Bourdieu's specific view of language as a power-broker in the field of teaching (Bourdieu, 1991) lends the researcher a method of interpretation that captures classroom interaction in terms of the value placed, consciously or unconsciously, on use of English by both teachers and children. A Bourdieusian view of language and literacy teaching highlights the ways in which each is a commodity that teachers barter, intentionally or unwittingly, in their relationships with pupils (Luke, 2008).

In essence, Bourdieu's ways of thinking about power relations, and the role of language as part of those relations, can uncover potential inequalities in the classroom and in the structure of educational policy (Grenfell, 2012). As numbers of children with English as an additional language (EAL) rise in schools in England, and the design of the new National Curriculum for English in England (DfE, 2013) focusses noticeably on a particular interpretation of English language and literature, "Bourdieu's trenchant vocabulary for talking about the systems of unequal and inequitable exchange in language and pedagogy ... is more relevant than ever." (Luke, 2008, p. 3).

In this article I put forward an argument for the use of Bourdieusian analysis combined with constructivist grounded theory as a way of exploring the teaching of English to English language learners through times of change in teachers' lives. I explore how policy for the teaching of English combined with expectations for the literacy outcomes of primary school children potentially impact negatively on the language and literacy development of EAL learners. In 
discussion I use the terms literacy and English interchangeably to reflect the way in which primary school teachers in England have come to use the two as synonymous, the way in which the curriculum promotes a similar conflation, and because the teaching of English language and literacy are central to the educational prospects of EAL learners meaning that impact of the one on the other is inseparable.

\section{Bourdieu and the Field of Literacy Teaching}

To introduce Bourdieusian thinking, his way of interpreting the actions of any one set of agents rests principally on the notions of field, habitus and capital (Bourdieu,1990). The field describes any arena in which agents operate; thus, for primary school teachers the field is defined by their school and their classroom, but also by the expectations of the curriculum. For the researcher, using field as a construct to frame the different expectations surrounding teachers' pedagogy can shed light on the full range of competing influences and expectations that teachers have to juggle.

For Bourdieu, the field moulds the behaviours of those operating within it. The resulting habits, beliefs and dispositions form the habitus and this governs the decisions that an individual will make in relation to their practice. Habitus is formed unconsciously in response to expectations of the environment in which agents live and work and has within it what Bourdieu identifies as doxa, which are unquestioned beliefs. Finally, the construct of capital is one generated by the extent to which an individual knows and plays by the rules of the field and is able to harness social, cultural or economic wealth. A sense of capital wealth, or absence of it, will be closely 
related to feelings of confidence or otherwise associated with the habitus. Thus, a teacher's habitus and accompanying sense of capital will, taking account of the expectations of the field, determine a teacher's practice ( Maton, 2012).

In Bourdieusian thinking one strand of capital relates specifically to language use because, he observes, language use can wield symbolic power (Bourdieu, 1991). Bourdieu argues that teachers perpetuate the use of a particular type of language which is recognised as more powerful than others and thus the standard against which all language use is measured (p.45). In England this would present itself as teachers and curriculum architects assuming the superiority of Standard English as a prized mode of communication. Thus, the English language itself is a form of capital, ownership of which acts as gatekeeper to educational success (Luke, 2008).

Within my own research I have found that the notions of linguistic field, linguistic capital and linguistic habitus in particular have allowed for the development of interpretive insight in to teachers' beliefs and practices for the teaching of English (Flynn, 2013). Policy for the teaching of English in England provides a field - a linguistic field - within which teachers must operate; one within which they know that they and their children have to conform to particular rules in order to succeed. The fact that policy, as curriculum, presents teachers with a way of behaving in the field - this becoming teachers' linguistic habitus - means that the curriculum generates its own rules which either tacitly or explicitly control the decisions teachers make in the classroom, and the decisions that are made at school level about the most appropriate ways for teaching English. Teachers' confidence to teach English well will be governed to some extent by their ownership of linguistic capital (Grenfell, 1996); linguistic capital can be defined in terms of 
teachers' subject knowledge for teaching English, as well as teachers' and children's fluency in using English. The teachers' linguistic habitus is thus shaped by a complex range of features for each individual related to experience, beliefs and subject knowledge for managing the differences in language and literacy skills of their pupils (Flynn, 2013).

Consider for example, the impact of the English National Literacy Strategy's 'clockface' on classroom practice for literacy teaching. The 'clockface' was a diagrammatic representation of the lesson outline, including timings for each part of the lesson, which was adopted as the pedagogy for delivery of the objectives within the National Literacy Strategy (DfES, 1998). In Bourdieusian terms this means that, in England, teachers' habitus, and consequently their classroom practice, was moulded by the expectations of this ambitious national initiative in literacy teaching; it became the field, and those who adopted its pedagogy for literacy teaching were game players who bought in to the importance of the very particular rules it laid out for classroom practice.

Consider also the fact that the curriculum for English is designed for native English speakers by native English speakers and, if we adopt a Bourdieusian definition of habitus as governing decisions unconsciously, this means that the potential for ignoring the needs of non-native speakers in educational policy for the teaching of English is always present. It also means that fluency in English acts as a source of capital in the classroom: fluency in 'the right sort' of English gives access to better educational outcomes for all children and to the development of cultural and social capital (Luke, 2008). 
In summary, a Bourdieusian interpretation of teachers' practice has the potential to unlock how teachers' linguistic habitus is related to expectations in the field of English teaching, to their sense of agency or otherwise to making pedagogical choices that rest on their beliefs (doxa) about the teaching of English, and to unspoken assumptions about the value of fluency in English.

\section{Defining Educational Policy for EAL through a Bourdieusian lens}

So, teachers' habitus relating to the teaching of English -their linguistic habitus - is shaped by the ways in which policy (the linguistic field) for the teaching of English shapes teachers' pedagogy. Arguably, paper-based documentation such as The National Curriculum for English (DfE, 2013) is not of itself policy; however, it is the channel through which policy becomes practice. Gerrard and Farrell (2012) note that, for Bourdieu, institutions play a lead in determining the way in which the field shapes its own rules. Schools make decisions about what they will accept, dismiss or ignore in any policy, and their subsequent decisions and actions therefore influence and organise educational practice in the classroom (p.2). Furthermore, where policy does become practice it is subject also to interpretation by groups and individuals; meaning that while governments have made attempts to control pedagogy for the teaching of English over several decades, the reality in class has always been filtered and modified through the ways in which the school has chosen to make meaning from the intentions of the policy makers (Moore, Edwards, Halpin, \& George, 2002). In this way teachers are subject not only to their own linguistic habitus in making decisions about how they teach English, but to the institutional habitus their school has developed as part of its inherent structure (Bourdieu, 1990, p.52). 
If we define teachers' subject knowledge for teaching English, and their automatic use of English as the language of instruction, as forms of linguistic capital or professional capital in the classroom, then it is perhaps surprising that the teaching of children with English as an Additional Language (EAL) is not conceived as a subject of itself. Teachers must, according to policy makers in England, develop a detailed understanding of the specifics of synthetic phonics teaching, but not of the ways in which first language and literacy development differs from additional language acquisition and literacy development for English language learners.

Leung (2001) draws our attention to the way in which EAL is constructed as a teaching and learning issue rather than a specific curriculum issue. This definition, he explains, means that the responsibility for delivering successful teaching and learning for children with EAL lies with teachers. This leaves policy-makers potentially freed from responsibility for the successful outcomes of EAL learners, and teachers perhaps unaware of how much there is to know and how much they do not know about the teaching of English as an additional language. Thus, schools' institutional habitus for the teaching of English is likely to be automatically aligned with the curriculum for English for monolingual speakers in the absence of anything else, and the idea that there might be a set of subject knowledge related to teaching EAL learners is left relatively unexplored; Leung also suggests that this limited exploration is matched by limited engagement from researchers in to effective EAL pedagogy. Bourdieusian analysis supports disambiguation: "a disconnecting of the articulated and disestablishing of the accepted" (Leung, 2001) that is needed in an exploration of how assumptions in policy have influenced the trajectory of support for EAL learners and how this support is positioned in the practice of teachers, the focus of researchers and the minds of policy makers. 


\section{Bourdieu as Method}

Bourdieusian social theory is important as a lens at a time of change because it potentially uncovers a game-plan that may be hidden to both its players and to those researching their actions. I have developed this view since completing a study in which I focussed on the responses of teachers who, working in settings unaccustomed to linguistic difference, experienced the arrival of Eastern European children in their classrooms following their home countries' accession to the European Union. Interviews conducted over two years (2007 - 2009) with ten primary school teachers in one authority, and other local authority personnel involved in EAL support, threw light on the ways in which policy governs practice and on the ways in which the habitus of the English teacher is moulded by the curriculum for native-English speakers (Flynn, 2013).

The interviews were structured to support research aims that sought to examine how primary school teachers might adapt their practice for the teaching of English (or literacy as they more commonly referred to it) in order that they could support the language acquisition and literacy development of their EAL learners. The overarching research aim was to explore and analyse the experiences and challenges for teachers of EAL learners in low-density EAL settings in terms of linguistic habitus and linguistic field. 
Methodologically the findings rested on analysis of the interview data using a marriage of computer software designed for qualitative analysis, and coding of the interviews employing constructivist grounded theory (Charmaz, 2006). The theoretical constructs from Bourdieu's writings were used to identify and name node families against which to code the data. The synthesis of constructivist grounded theory with Bourdieusian analysis was chosen because I perceived a synergy between the two. Charmaz' view that grounded theory generates a 'discovered reality' that is time and place-bound socially and politically (Charmaz, 2000, p. 524) partners Bourdieu's view that use of his methodological toolkit can uncover multiple layers of interpretation that are profoundly subject to contextual influence.

Data analysis underwent several iterations in order to reach the most useful way of defining the node families against which the interview transcripts could be coded. The Bourdieusian notions of field, habitus and capital were used as parent nodes, and there were subdivisions within each which depicted the ways in which teachers' responses manifested themselves as evidence of one or several. The nodes allowed for analysis of patterns of behaviour as expressed in the teachers' descriptions of their practice (defined as capital in order to reflect teachers' subject knowledge) and a tracing of where the field was interacting with teachers' professional choices (coded chiefly as habitus) in the classroom in relation to their teaching of English. Furthermore it supported the analysis of layers of social, cultural and linguistic capital attributable to the EAL learners, their parents and their teachers.

Nodes relating to the construct of 'field' reflected a range of themes generated in conversation with the teachers. The key nodes were defined as 'Tensions', 'Curriculum Influences', 'Learning 
Communities', 'School Philosophy', 'Migration Impact' and 'Limited EAL Training'. These themes related to the structuring of the field in terms of the expectations of the curriculum, resourcing, teachers' reference to the support of others in their learning communities, and the impact of new migration on the pupil intake in their schools. Within each node sat subsets such as those causing tensions - limited funding and limited resources - or those showing what influenced curriculum design, such as pupils' ages or policy related expectations. The nodes related to field emerged quite readily from what the teachers said: for example they would refer explicitly to the influence of the Primary National Strategy for English (DfES, 2006) on their teaching which was coded as Field - Curriculum Influence - Policy Related; or to something that was a barrier to their capacity to teach English to EAL learners which would have been coded within Field - Tensions.

Coding habitus and capital was more complex; not least because all of the constructs in Bourdieu's methodological toolkit are inter-dependent and separation of one from the other is not necessarily possible or desirable (Bourdieu \& Wacquant, 1992). For some, Bourdieu's determinism is problematic in interpreting the actions of agents, and it was difficult at times to avoid becoming negative about teachers' habitus; as if they had control over what is in fact an unconscious driver in decision making.

As habitus is chiefly related to unconscious behaviours and dispositions, transcripts were more actively subject to my interpretation of what teachers' responses might indicate. In essence, what made the habitus nodes different was that the transcript extracts coded against them demonstrated a mind-set towards the teaching of English for either monolingual (L1) or EAL 
(L2) learners rather than a description of the teachers' understanding. For example, most demonstrated the pragmatism in relation to accepting policy expectations that was identified by Moore et al (2002) as belonging to teacher identity following decades of centralised curriculum reform and this was captured within the node 'Teacher as Pragmatist'. The node 'Teacher Confidence' was used to group transcript extracts against either a confidence or a lack confidence in the teaching of EAL learners. This later became linked with the notions of professional or linguistic capital as feelings of ownership of either of these appeared to support either a confident or an anxious habitus. 'Teacher as Carer' was a node evident in all transcripts and this captured teachers' desire to do the best by their pupils. Transcripts coded against this node might also be included in the node 'Teacher Anxiety' which reflected teachers' feelings that they could not necessarily deliver the best for their EAL learners.

The nodes related to capital were the most intricate, often interdependent, and the most numerous. The coding of transcripts for capital required initial subdivision in to types of capital: Linguistic Capital, Professional Capital (Experience) and Professional Capital (Subject Knowledge). This was relatively straightforward for the constructs of social and cultural capital coded for this project as Professional Capital - because these are defined extensively in the literature both by and about Bourdieu. The term 'linguistic capital' is used by Grenfell (1996) and was a meaningful analytical theme for a project with a central focus of English learning and teaching. Within Linguistic Capital the node related to fluency in English in particular needed third level sub-divisions because of the number of different ways in which teachers referred to fluency in relation to attainment. This included comments on children's fluency, on their parents' 
fluency, and on parents' and children's confidence to speak in English. These references often suggested a relationship between fluency and social or cultural capital.

'Professional Capital' was a term that emerged after several rounds of coding the data with a view to distilling teachers' subject knowledge (cultural capital) for teaching English. Originally I had attempted to code subject knowledge as a node of itself, and as part of linguistic capital, but over time and re-readings of the transcripts the nature of teachers' subject knowledge as complex and many-layered rendered coding in this way unhelpful. 'Professional Capital' as a term allowed me to capture teachers' experiences and understanding in ways that reflected the sometimes overlooked multifaceted nature of teachers' subject knowledge (Elbaz, 1981; Fenstermacher, 1994).

Division of habitus and capital was helpful at the coding stage, but when it came to further analysis and the generation of theory relating to the data, the nodes Linguistic Capital and Professional Capital, for example, felt largely synonymous with notions of linguistic and professional habitus: considering some of the node titles within capital they might just as easily have sat within habitus. Later discussion in this article shows that this potential limitation was also a strength of the method, because teachers' description of what they 'know' about the teaching of English of itself betrays a mind-set for the teaching of English: thus, thinking in terms of both capital and habitus gives the researcher the potential to see the relationships between the two. 


\section{Disambiguating policy and practice for the teaching of English}

Following coding of the interview data there were a range of ways in which to respond to the emerging themes, but something that stood out from early on in data analysis was a disparity in the weighting of coding relating to different areas of literacy teaching in the teachers' discourse. There was much in the conversations with them about their teaching of English to monolingual speakers that identified how powerful the hold of the English curriculum was on their beliefs about teaching. Rather than expressing and articulating their own beliefs about teaching English they tended more to talk about what they did while teaching English and relate this to the curriculum documentation that was current at the time. In this way, identifying the linguistic field as a construct for interpreting the teachers' responses, made clear the extent to which years of centralised curriculum has unconsciously influenced practice (Moore, et al., 2002) and to which policy related to assessment manipulates practice (Fisher, 2004).

Two key questions asked of the teachers were 'What would you describe as key to your successful teaching of English for your monolingual children?' and 'How do you think this is different for second language learners?' The diagrams below demonstrate how this manifested itself in the coding process (Figures 1 and 2). In handling qualitative data it is difficult to capture a notion of weighting or significance, but there was a clear weighting regarding the amount of transcript coded against different types of literacy teaching and this demonstrated what teachers felt was important in their teaching. Figure 1 shows the weighting or density of transcript coded within broad categories of English teaching for monolingual learners. 
Figure 1 Coding teachers' discourse about their practice for teaching monolingual learners
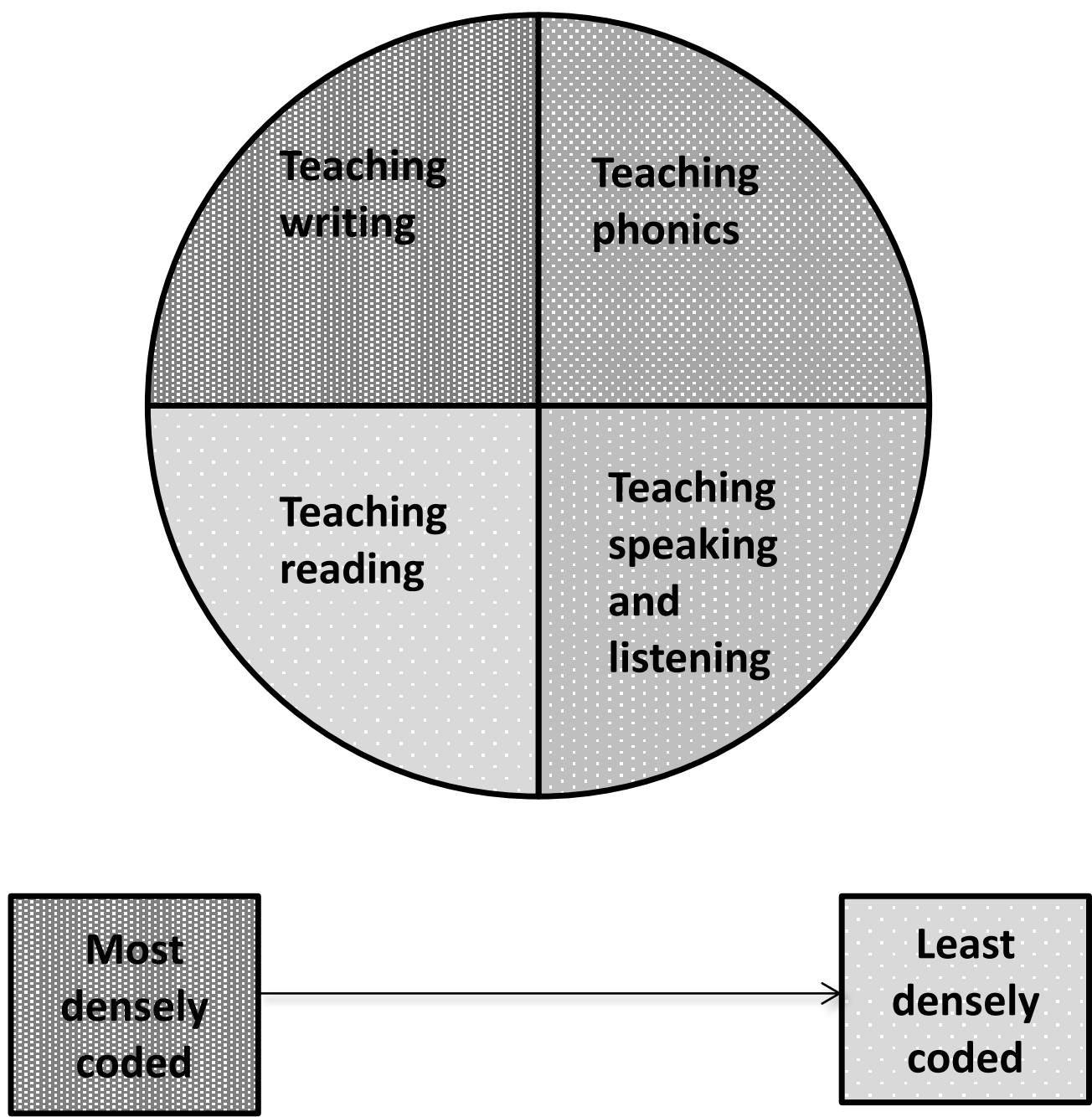

Interestingly the teachers talked most about their teaching of writing when explaining their practice. They were focussed on end points and assessable learning outcomes rather perhaps than on the journey to those outcomes. This was the case particularly for teachers in Key Stage 2 (7 11 year olds) who were preoccupied with measurement of children's literacy skills as belonging most significantly to their writing. There was reference to use of spoken English, but more often than not this related to 'talk for writing'; thus, talk was part of a journey towards what was perceived as a measurable outcome, rather than being an outcome of itself. The emphasis on phonics, the second most densely coded area, was related to a very particular policy shift in the 
teaching of reading around 2006, defined in the publication an Independent Review of the Teaching of Early Reading (Rose,2006), by which teachers felt heavily directed .

Here the linguistic habitus - what is expressed as teachers' perceptions of good practice for teaching English by the teachers - was clearly defined by what they saw as important in the curriculum. In this way it became apparent that teacher habitus is perhaps defined by the curriculum and expectations of assessment, and it is difficult to untangle what teachers feel they must do with the curriculum from what teachers might believe is good practice.

Observe that these nodes started life within the node family related to capital, but ended up as part of the picture of teachers' beliefs and a portrait of what they know and value in the teaching of English. Thus, the coding process indicated that what teachers know (capital) and what they believe or do (habitus) are largely inseparable and it is in this combined separation and intertwining of coding that the strength of thinking along Bourdieusian lines is apparent. The logic of practice supports a relational data analysis that encourages depth of interpretation through layers in qualitative enquiry (Pahl, 2012). I don't suggest that finding relationships in the data is unproblematic: navigating where the joins were was of course subject to my own context and the context in which the teachers were operating. However, acknowledgment of subjectivity is key to both a Bourdieusian interpretation of practice and a constructivist grounded theory approach to data analysis. 
Figure 2, Coding teachers' discourse about their practice for their EAL learners
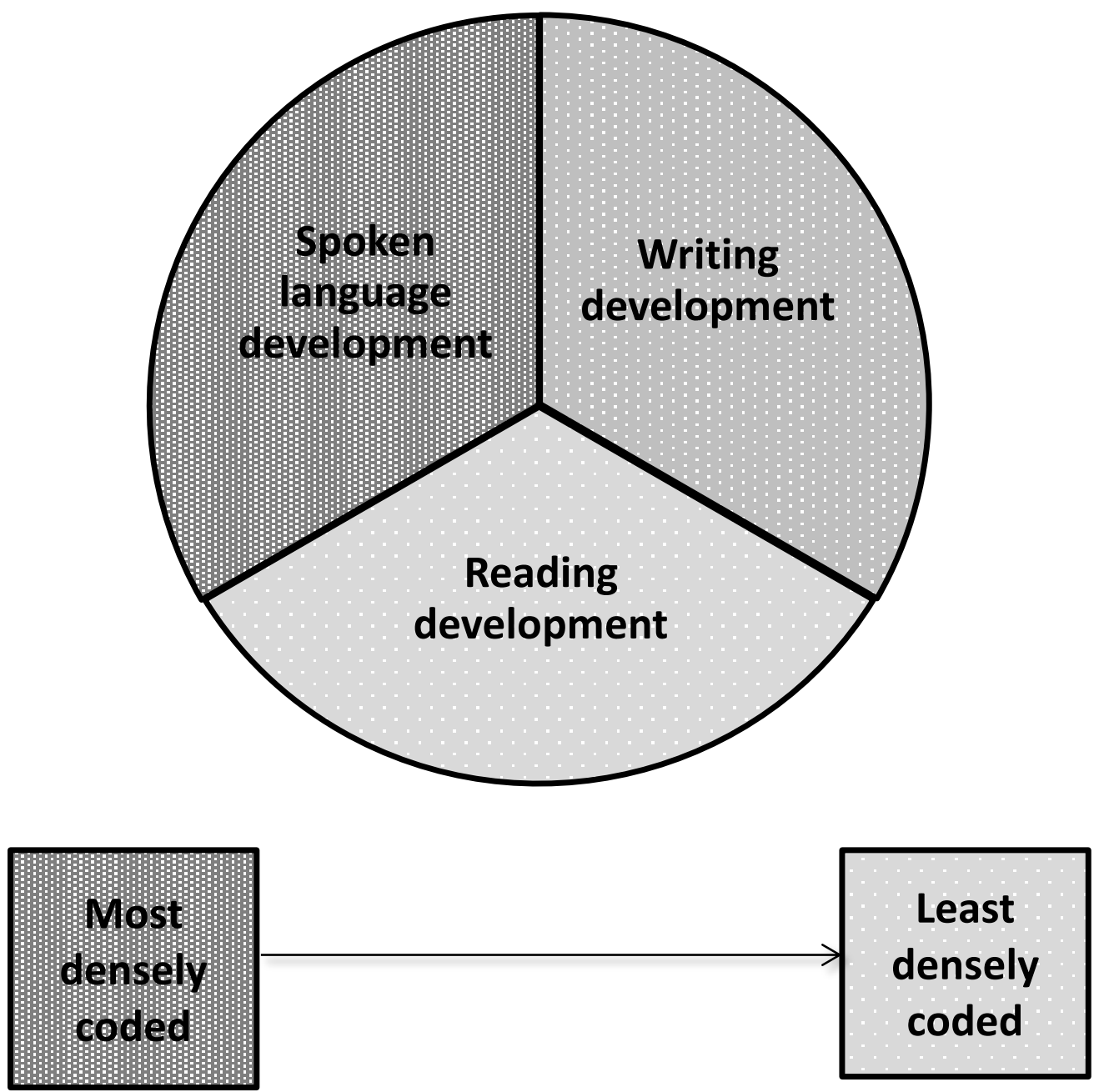

The density of coding when teachers were talking about how they should adapt their teaching for second language learners drew a different picture from what they prioritised as important for the teaching of monolingual learners (Figure 2). There was an understanding that EAL learners need a talk-based curriculum, demonstrated by the weighting of coded transcripts referring to spoken English, but the emphasis of discourse moved quickly to aspects of writing. Thus, the teachers had some subject knowledge (linguistic capital) for the teaching of EAL but the fact that there 
was not much discussion of the teaching of reading as a precursor to writing, or the teaching of phonics to give EAL learners a grounding in English letters and sounds demonstrated that some teachers' understanding had gaps. It also perhaps indicated teachers' tendency to compartmentalise their teaching. On the one hand, seeing a difference in how teachers conceptualise their teaching for different learner groups should be cause for celebration, but when taken alongside the detail of the transcripts it appeared that while teachers understood what they should do, they did not necessarily feel that they could teach in ways suited to second language acquisition or literacy development. This field-related tension between what teachers knew and what they felt able to do was a key finding in the interview analysis and is reported elsewhere (Flynn, 2013). It is important to note that throughout the interviews teachers' commitment to inclusive practice for their EAL learners was strongly in evidence; but it was their lack of a sense of agency to act on this fully that arose clearly from the data.

Uncovering Inequalities: the positioning of EAL teaching within the field for teaching English

Comparison of figures 1 and 2 highlights significant differences in the way that teachers articulated their practice for monolingual and for EAL learners, and this led to further exploration of the transcript detail and coded themes in order to uncover possible causes for the ways in which they differed.

During data analysis, disjuncture was something that emerged powerfully from the transcripts in terms of teachers' feelings of anxiety about their English teaching when faced with the task for successfully developing language and literacy in their EAL learners. By this I mean a disjuncture 
between the written curriculum and teachers' subject knowledge: EAL teaching and learning appears to compete unsuccessfully with the demands of teachers' practice for monolingual learners.

Key to interpreting teachers' view of their own subject knowledge for teaching EAL learners was that it appeared to begin with their understanding of the curriculum for English which is aimed at a pupil group who speak English as their first language (Safford \& Drury, 2013). Thus, the curriculum for L1 (English for a monolingual speaker) sits always in a superior position to that of L2 (English for a non-native speaker. It was also the case that in describing their practice teachers demonstrated that their experiences and understanding generated their beliefs about the teaching of English to either L1 or L2 learners. Furthermore, the reference by many of the group to the curriculum for English meant that the monolingual linguistic field was apparent in dialogue relating to understanding (linguistic capital) and practice (linguistic habitus) much of the time.

The field for literacy teaching appeared to have a missing link which laid in the lack of any reference to the curriculum for L2; there was no reference to a range of supporting documentation such as Excellence and Enjoyment: Learning and Teaching for Bilingual Children in the Primary Years and others available at the time (DCSF, 2006, 2007, 2009). Thus, in teachers and in policy-makers minds the curriculum for EAL learners sat only as an appendix to the curriculum for monolingual learners (Leung, 2001). In this way, the application of Bourdieusian analysis through constructivist grounded theory uncovered a singular inequality in both the teachers' practice and in the shaping and positioning of curriculum materials for EAL 
learners in the field at the time. Teachers demonstrated that their linguistic habitus was defined chiefly by the curriculum for their native-speakers and this supports the view that EAL learners are habitually framed through a monolingual planning and assessment framework which disadvantages their potential to make progress (Safford and Drury, 2013).

\section{Conclusion}

In setting the context for this article reference was made to the observations of Leung that the curriculum for EAL is subsumed in to a curriculum for monolingual speakers as a teaching and learning issue, and that research in to exploring effective pedagogy for EAL is limited (Leung, 2001). While there is considerable research in to EAL in terms of applied linguistics, there is a view that this is not matched by practice-based research that can foster an informed workforce for teaching EAL learners (Andrews, 2009). The discussion of data in this article adds to this debate. It was apparent that, even in the face of a change in their pupil demographic, and with explicit recognition of differing learning needs in learning English language and literacy, that teachers found it difficult to adapt their teaching for their EAL learners. Such teaching was not necessarily recognised as something with which they needed explicit support in the form of the development of new subject knowledge. It also became apparent in my review of the range of literature surrounding the curriculum for English between 1998 and 2010 that researchers themselves have devoted limited time to commentary on the published curriculum documents 
that could support EAL learners, and this was compounded by the fact that teachers seemed unaware of their potential value.

However, the use of Bourdieu and constructivist grounded theory to untangle policy and practice does more than simply add weight to the evidence base for Leung's critique. Rather, the use of this combined method allows the researcher insight in to the way that policy shapes teachers' lives, and thus to see where habits are changing or remain unchanged. In this way, the researcher has an opportunity to present alternative points of view that do more than berate governments for getting policy wrong or unsupported teachers for failing to adapt to changing circumstances. The researcher can position commentary in a manner that draws a threedimensional portrait of a status quo and asks 'why does this happen and what can we do about it?' rather than 'why doesn't this work?'

For example, in identifying differences between the ways that teachers conceptualised their practice for each group of learners, this researcher was given the signal to further explore the positioning of policy documentation relating to EAL learners. This inequality in the positioning of curriculum guidance may have remained invisible had the context of the linguistic field not been matched to exploration of what the teachers expressed as linguistic habitus. Thus the application of context and personal or institutional history required by both Bourdieu and a constructivist grounded theory approach to data analysis is powerful in directing enquiry towards areas that may otherwise remain uncovered. It also lays open a pathway for constructive discussion with professionals about their practice rather than the adoption of a blame culture when pupil needs are perceived as not met. 
The interviews with teachers discussed in this article were conducted at a time of change for the teachers involved. This shift came in the shape of a more linguistically-diverse pupil population, but also at a time of policy-related review that looked set to change the curriculum for one based on a cross-curricular and cross-skills basis that potentially supported language development for all learners (Alexander, 2010; Rose, 2009). However, the incoming government in 2010 had a different agenda to set, and teachers of English in England sit currently with policy documentation that could be described as bound up with an English national identity that masks the diverse nature of English classrooms. Thus, Bourdieusian notions of the imposition of one form of language as having greater value than another are perhaps present in the design and the intended implementation of the new curriculum for English.

As the pupil demographic continues to change in English schools to one where greater numbers of EAL learners are a norm, and as the new curriculum negotiates a path that appears to indicate a monolingual English habitus, it is important that research in to the teaching of English seeks to explore the inequity that either of those changes might generate. Bourdieusian interpretation of policy and practice sheds light on these potential inequalities in our pedagogy for language and literacy and supports dialogue towards improvement that embraces past histories and how they shape our present practice. 
Alexander, R. (Ed.). (2010). Children, their World, their Education. London: Routledge.

Bourdieu, P. (1990). The Logic of Practice (R. Nice, Trans.). Cambridge: Polity Press.

Bourdieu, P. (1991). Language and Symbolic Power. Cambridge: Polity Press.

Bourdieu, P., \& Wacquant, L. (1992). An Invitation to Reflexive Sociology. Cambridge: Polity Press.

Charmaz, K. (2000). Grounded Theory: Objectivist and Constructivist Methods. In N. K. Denzin \& Y. S. Lincoln (Eds.), Handbook of Qualitative Research (2nd ed., pp. 509 - 535). London: Sage.

Charmaz, K. (2006). Constructing Grounded Theory: A Practical Guide Through Qualitative Analysis. London: Sage.

DCSF. (2006). Excellence and Enjoyment: Learning and Teaching for Bilingual Children in the Primary Years.

DCSF. (2007). New Arrivals Excellence Programme (No. 00650-2007BKT-EN). Nottingham: DCSF.

DCSF. (2009). Ensuring the Attainment of More Advanced Learners of English as an Additional Language (EAL) (No. 00045-2009). Nottingham: DCSF.

DfE. (2013). National Curriculum in England: English programmes of study: www.education.gov.uk/nationalcurriculum.

DfES. (2006). Primary Framework for Literacy and Mathematics. Nottingham: DfES Publications.

Elbaz, F. (1981). The Teacher's "Practical Knowledge": Report of a Case Study. Curriculum Inquiry, 11(1), 43 - 71. 
Fenstermacher, G. (1994). The Knower and the Known: The Nature of Knowledge in Research on Teaching. Review of Research in Education, 20, 3 - 56.

Fisher, R. (2004). Embedding the Literacy Strategy: Snapshots of change? . Literacy, 38(3), 134 $-140$.

Flynn, N. (2013). Linguistic capital and the linguistic field for teachers unaccustomed to linguistic difference. British Journal of Sociology of Education, 34(2), 225 - 242.

Gerrard, J., \& Farrell, L. (2012). “Peopling' curriculum policy production: researching educational governance through institutional ethnography and Bourdieuian field analysis.'. Journal of Curriculum Policy, 28(1), 1 - 20.

Grenfell, M. (1996). Bourdieu and Initial Teacher Education: A Post-Structuralist Approach. British Educational Research Journal, 22(3), 287 - 303.

Grenfell, M. (2012). Bourdieu, Language and Education. In M. Grenfell, D. Bloome, C. Hardy, K. Pahl, J. Rowsell \& B. Street (Eds.), Language, Ethnography and Education (pp. 50 70). London: Routledge.

Grenfell, M., \& James, D. (Eds.). (1998). Bourdieu and Education: Acts of Practical Theory. London: Routledge.

Leung, C. (2001). English as an Additional Language: Distinct Language Focus or Diffused Curriculum Concerns? . Language and Education, 15(1), 33 - 55.

Luke, A. (2008). Pedagogy as Gift. In J. Albright \& A. Luke (Eds.), Pierre Bourdieu and Literacy Education (pp. 68 - 92). London: Routledge.

Maton, K. (2012). Habitus. In M. Grenfell (Ed.), Pierre Bourdieu: Key Concepts (second edition) (pp. 48 - 64). Durham: Acumen Publishing 
Moore, A., Edwards, G., Halpin, D., \& George, R. (2002). Compliance, Resistance and Pragmatism: the (re)construction of schoolteacher identities in a period of intensive educational reform. British Educational Research Journal, 28(4), 551 -565.

Pahl, K. (2012). Seeing with a Different Eye. In M. Grenfell, D. Bloome, C. Hardy, K. Pahl, J. Rowsell \& B. Street (Eds.), Language, Ethnography and Education: Bridging New Literacy Studies and Bourdieu (pp. 89 - 109). London: Routledge

Rose, J. (2006) Independent Review of the Teaching of Early Reading, Nottingham:DfES

Rose, J. (2009). Independent Review of the Primary Curriculum: Final Report. Nottingham: DSCF Publication.

Safford, K., \& Drury, R. (2013). The 'problem' of bilingual children in educational settings: policy and research in England. Language and Education, 27(1), 70 - 81. 